\title{
Poetik und Intertextualität der Johannesapokalypse
}

\author{
Hrsg. v. Stefan Alkier, Thomas Hieke u. Tobias Nicklas, in Zus.-Arb. m. Michael
} Sommer

Poetik und Intertextualität der Johannesapokalypse

Herausgegeben von STEFAN ALKIER, THOMAS HIEKE und TOBIAS NICKLAS

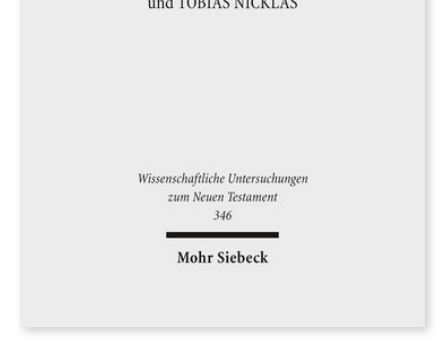

2015. IX, 475 Seiten. WUNT I 346

ISBN 978-3-16-153547-5 DOI 10.1628/978-3-16-153547-5 eBook PDF $174,00 €$ ISBN 978-3-16-152966-5 Leinen $174,00 €$
Die Erforschung der Johannesapokalypse hat in den vergangenen Jahren einen Paradigmenwechsel erfahren: während der Text lange Zeit als das Werk eines oder mehrerer Autoren angesehen wurde, die des Griechischen kaum mächtig waren und sich weit von der ursprünglichen Botschaft Jesu entfernt hatten, und während angebliche Brüche in der Konzeption immer wieder zu gewagten literarkritischen Hypothesen führten, kristallisiert sich heute mehr und mehr heraus, dass wir es mit einem höchst durchdachten, wenn auch spannungsvollen, in mancher Hinsicht einzigartigen literarischen Werk von erstaunlicher Qualität und theologischem Gewicht zu tun haben. Die Beiträge des vorliegenden Bandes, der aus den Vorträgen einer interdisziplinären Frankfurter Tagung des Jahres 2012 erwachsen ist, zieht einige der damit angedeuteten Linien noch weiter aus. Neu gewürdigt wird die Sprache der Apokalypse wie ihre stilistische und literarische Konzeption. Der Band stellt Raum- und Zeitmodelle in der Johannesapokalypse vor und fragt nach der Bedeutung des »Buches« für die Gesamtkonzeption des Textes; dazu das Problem diskutiert, inwiefern die Johannesapokalypse als »phantastische Literatur « bezeichnet werden könne. Eine Reihe von Studien beschäftigt sich mit intertextuellen Bezügen der Johannesapokalypse. Dabei liegt naturgemäß ein Schwerpunkt auf dem Verhältnis des Textes zu Schriften und Motiven des Alten Testaments wie des frühen Judentums; neu gestellt jedoch werden auch Fragen nach dem Zueinander zum Vierten Evangelium oder zu Schriften der hellenistisch-römischen Welt wie zu Aspekten ihrer Rezeptionsgeschichte.

Inhaltsübersicht

\section{Philologie und Textgeschichte}

Thomas Paulsen: Zu Sprache und Stil der Johannes-Apokalypse - Dieter Zeller: Zum Tempusgebrauch in der Offenbarung des Johannes - Martin Karrer: Textgeschichte und Demarkationsprozesse der Johannesoffenbarung - Jörg Frey: Das Corpus Johanneum und die Apokalypse des Johannes. Die Johannes-legende, die Probleme der johanneischen Verfasserschaft und die Frage der Pseudonymität der Apokalypse - Arthur Manukyan: Die Johannesapokalypse und die armenischen Bibelübersetzungen im Wandel der Zeit - Ertrag, Tendenzen und Perspektiven der Forschung

\section{Poetologische Untersuchungen}

Peter v. Möllendorff: »Nimm und verschling es! « Elemente einer Poetik der Johannes-Apokalypse - Marco Frenschkowski: Apokalyptik und Phantastik. Kann die Johannesoffenbarung als Text phantastischer Literatur verstanden werden? Ein Essay Stefan Alkier/Tobias Nicklas: Wenn sich Welten berühren. Beobachtungen zu zeitlichen und räumlichen Strukturen in der Apokalypse des Johannes - Robyn J. Whitaker: The Poetics of Ekphrasis. Vivid Description and Rhetoric in the Apocalypse Annette Weissenrieder: Bilder zum Sehen - Bilder zum Hören? Über die Grenzen von visuellem Bild und Sprache als Ekphrasis in Apk 17

\section{Intertextualität und Intermedialität}

Thomas Hieke: Die literarische und theologische Funktion des Alten Testaments in der Johannesoffenbarung - Adela Yarbro Collins: Rewritten Prophets. The Use of Older Scripture in Revelation - Edmondo F. Lupieri: From Sodom and Balaam to the Revelation of John. Transtextual Adventures of Biblical Sins - Michael Sommer: Pech und Schwefel. Das Motivfeld Sodom und der Tag YHWHs in der Offenbarung - Luca Arcari: Vision and Tradition. Authoritative Past in the Reconfiguration of Visionary Experiences according to the Revelation to John The Son of Man in Rev 1:7.12-20 - Jan Willem van Henten: The Intertextual Nexus of Revelation and Graeco-Roman Literature - Daniele Tripaldi: Der Geist und das Gedächtnis. Die Johannesoffenbarung als prophetische Erinnerung an Jesusworte - Ian Boxall: Riding White Horses. An Intertextual Study of Rev 6:1-2 in the Light of its Reception History - Sotirios Despotis: Die himmlische Liturgie der Apokalypse (Kap. 4-5) in ihrem Kontext und die Interaktion mit der östlichen irdischen Liturgie

Stefan Alkier Geboren 1961; Studium der Ev. Theologie, Germanistik und Philosophie in Münster, Bonn und Hamburg; 1993 Promotion; 1999 Habilitation; seit 2001 Professor für Neues Testament und Geschichte der Alten Kirche am Fachbereich Evangelische Theologie der Goethe-Universität Frankfurt am Main.

Thomas Hieke Geboren 1968; 1996 Promotion; 2003 Habilitation; seit 2007 Professor für Altes Testament an der Johannes Gutenberg-Universität Mainz.

Tobias Nicklas Geboren 1967; 2000 Dr. theol.; 2005-07 Professor für Neues Testament an der Radboud Universität Nimwegen, Niederlande; seit 2007 Professor für Exegese und Hermeneutik des Neuen Testaments an der Universität Regensburg; Research Associate an der University of the Free State, Bloemfontein, Südafrika; seit 2018 Leiter des Centre for Advanced Studies »Beyond Canon« an der Universität Regensburg; seit 2019 Adjunct Ordinary Professor an der Catholic University of America, Washington, D.C., USA. https://orcid.org/0000-0002-1021-6994

Michael Sommer Geboren 1984; 2014-20 Juniorprofessor für Bibelwissenschaften an der Martin-Luther-Universität Halle Wittenberg; 2020-22 Vertretungsprofessuren für Neues Testament an den Universitäten München, Regensburg und Duisburg-Essen; aktuell Privatdozent für Neues Testament an der Universität Regensburg. 
Jetzt bestellen:

https://mohrsiebeck.com/buch/poetik-und-intertextualitaet-der-johannesapokalypse-9783161535475?no_cache=1

order@mohrsiebeck.com

Telefon: +49 (0)7071-923-17

Telefax: $+49(0) 7071-51104$ 